\title{
¿Es una ley garantía de protección del patrimonio? Previsión, prevención y negociación como posibles alternativas de protección
}

Àngel Galobart | director del Museu de la Conca Dellà y Dinosfera; jefe del grupo de investigación del Mesozoico del Institut Català de Paleontologia Miquel Crusafont

URL de la contribución <www.iaph.es/revistaph/index.php/revistaph/article/view/4160>

Recientes casos que han afectado gravemente una parte del patrimonio paleontológico en diversos yacimientos de Catalunya nos permiten abrir una reflexión sobre la eficacia y eficiencia del marco legal vigente.

Como introducción recordaremos que en el caso de Catalunya la ley vigente es la de octubre de 1993, que incluye un amplio abanico de bienes patrimoniales, entre ellos la paleontología. La ley describe las categorías de protección del patrimonio paleontológico y hace especial hincapié en el papel del propietario en relación con la conservación de los bienes culturales que se encuentren en su propiedad. Este factor puede llegar a convertirse en un problema, más que en una solución, en algunos casos, principalmente cuando estamos hablando de pro- pietarios particulares que se ven en la obligación de conservar un patrimonio que, por ley, es de todos.

Dos casos pueden resumir las diferentes problemáticas que podemos encontrar en relación con la protección del patrimonio: pérdida de patrimonio por causas naturales (yacimiento de icnitas de dinosaurio de Fumanya) y pérdida de patrimonio por actos vandálicos (yacimiento de huevos de dinosaurio de Coll de Nargó, Lleida).

El primer caso se refiere al yacimiento de Fumanya (Barcelona), catalogado como bien cultural de interés nacional y corresponde a un afloramiento de más de un kilómetro y medio de longitud, con cerca de 3500 huellas de dinosaurio que se encuentra al aire libre, sujeto
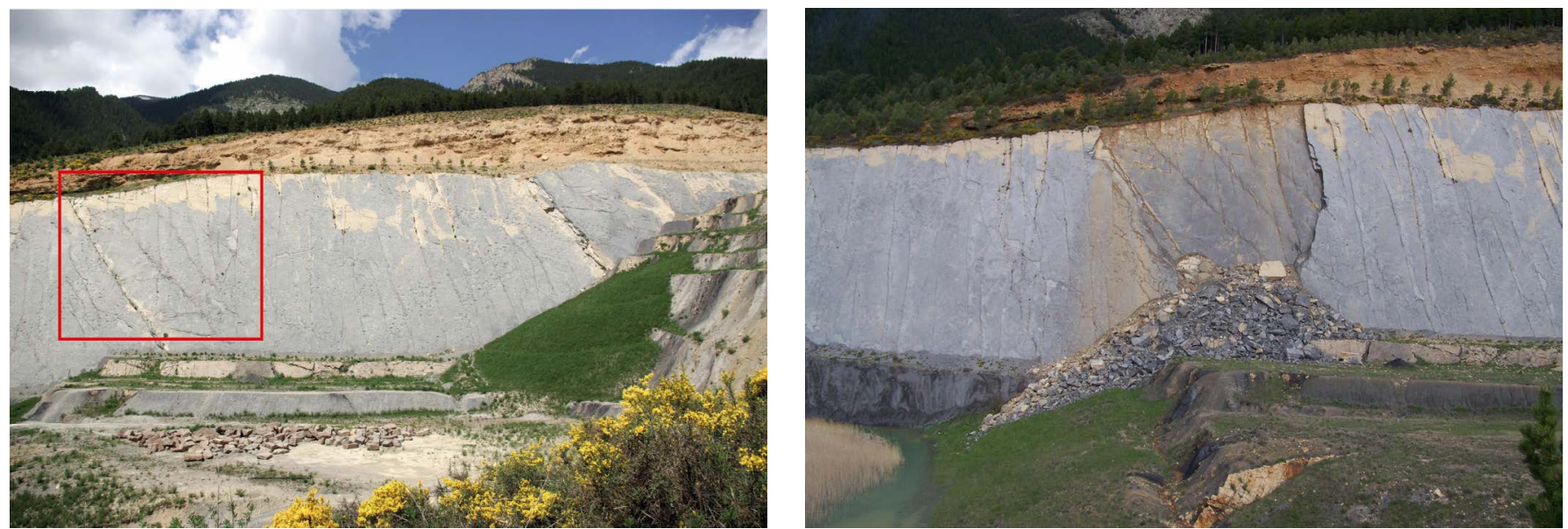

Vista del desprendimiento en el yacimiento de icnitas de Fumanya Sud. A la izquierda una vista del yacimiento con un recuadro que señala la zona del desprendimiento. Derecha, magnitud del desprendimiento en el yacimiento | Institut Català de Paleontologia 
a debate El marco legal para la protección del patrimonio paleontológico. ¿Qué pasa en tu comunidad?

a las inclemencias de la temperatura propia de alta montaña. Este yacimiento se descubrió gracias a la realización de una mina de carbón a cielo abierto a mediados de los años 80. Los hallazgos nunca fueron comunicados al organismo competente para la gestión del patrimonio paleontológico pero sí al organismo que regula la extracción de minerales y recuperación de canteras a cielo abierto, con el objetivo mal disimulado de evitar reparar el terreno. A finales de siglo aparecen los primeros artículos científicos y los recientes propietarios de la cantera (Endesa) reúnen a paleontólogos, técnicos de la administración y alcaldes de la zona para consensuar medidas de protección y dinamización de la zona. Sin previo aviso Endesa cede el terreno, ya sin interés económico, a los municipios, y con esta cesión la responsabilidad de proteger el yacimiento recae en estos últimos. Un yacimiento de estas características (paredes verticales de más de 60 metros de altura, en una zona con parte del año completamente cubierta de nieve) sólo tiene una mínima posibilidad de conservación si se aplica un plan de saneamiento de escorrentía de aguas y se cubre de las inclemencias meteorológicas. Teniendo en cuenta que la crisis económica frena cualquier tipo de inversión faraónica como una cubierta parcial, solo queda aplicar un plan de saneamiento de la zona superior del yacimiento. Estos trabajos, proyectados por geólogos e ingenieros en al año 2005 y valorados en un $60.000 €$, no se llevaron nunca a cabo y, diez años después, un gran desprendimiento cercenaba buena parte del yacimiento paleontológico en una zona situada en frente del centro de interpretación que se inauguraría un par de años después del derrumbe.

Este caso es paradigmático por declarar como BCIN una estructura geológica que claramente no se puede proteger, y menos aún por sus propietarios, que son municipios de centenares de habitantes y sin recursos económicos. No obstante, y previendo la desintegración del yacimiento, los científicos encargados de su estudio (geólogos de la UAB y paleontólogos del Institut Català de Paleontologia) llevaron a cabo una digitalización de todo el yacimiento utilizando un LiDAR-scanner que ha permitido preservar, digitalmente, el patrimonio ya desaparecido.
El segundo caso que presentamos conlleva unos tintes kafkianos difíciles de comprender. La geología de Coll de Nargó (Lleida) nos ha proporcionado unos excepcionales yacimientos de huevos y nidos de dinosaurio que se extienden por varios quilómetros cuadrados. Esta riqueza paleontológica ha puesto en órbita internacional los afloramientos Maastrichtienses del Pirineo y se han propuesto nuevas hipótesis sobre el comportamiento reproductivo de los dinosaurios saurópodos. Esta riqueza patrimonial es la base de un proyecto de divulgación (Dinosaurios de los Pirineos) que quiere mostrar el patrimonio en centros de interpretación próximos a los yacimientos (caso de Dinosfera en Coll de Nargó o el Museu de la Conca Dellà en Isona). Uno de estos centros corresponde al "Mirador del Cretaci", un espacio a cielo abierto musealizado con un camino y unas pasarelas que recorren y muestran diversos elementos fósiles como son restos vegetales, pisadas o restos de huevos conservados en una margocaliza de gran dureza. Este espacio se inauguró en el año 2008, con gran afluencia de público, y en el año 2013 se excavó un pequeño esqueleto de un vertebrado que se encontraba entre los restos de huevos de dinosaurio. Durante la última noche

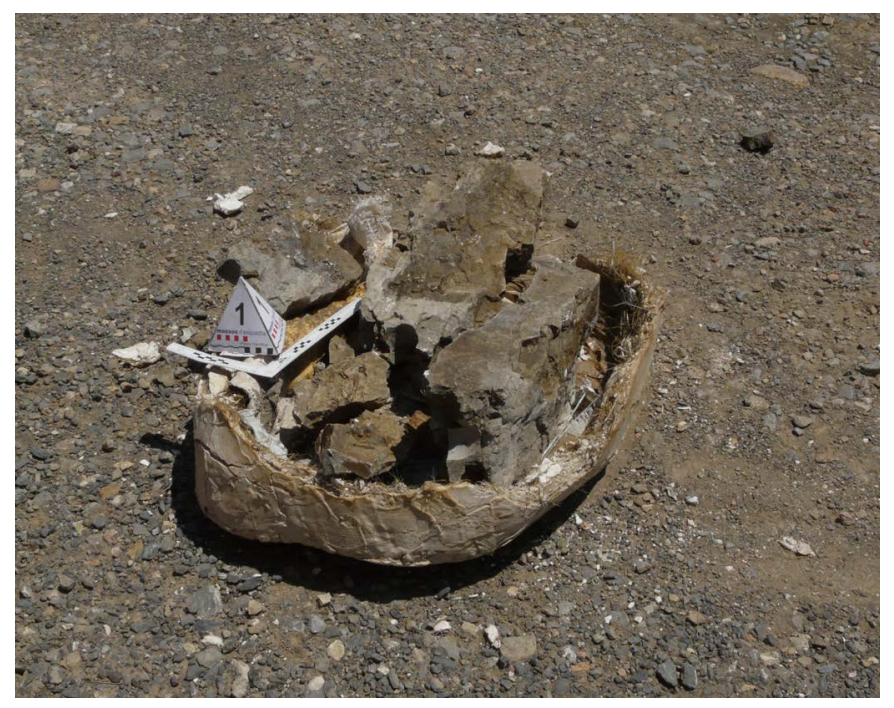

Bloque de yeso con los fragmentos de sedimento rotos depositados cerca del yacimiento. El autor del robo rompió y manipuló el bloque de sedimento en busca de los fósiles | Institut Català de Paleontologia 
de la excavación alguien sustrajo el bloque de sedimento con el fósil, ya preparado para su extracción. Durante aproximadamente un mes, la brigada de patrimonio de los Mossos de Esquadra llevó a cabo una meticulosa investigación que desembocó en una presión extremada sobre el presunto autor de robo. Una llamada anónima alertó de que el bloque con el fósil se había depositado cerca del yacimiento, esta vez completamente roto y con la pérdida irreparable de parte del fósil. Finalmente se detuvo al propietario del terreno como autor del robo del fósil y fue juzgado a principios del año 2015. Por razones desconocidas no se presentó al juicio la defensa de la Generalitat de Catalunya, a pesar de haberse realizado una cuantificación de los daños sufridos por el fósil, de forma que el juez dictaminó una multa de $6 €$ durante quince días.

En el mes de julio del mismo año el yacimiento de huevos de dinosaurio amaneció completamente destrozado. Las casi dos decenas de huevos de dinosaurio habían sido destrozados de forma metódica y contumaz. La brigada de patrimonio llevó a cabo otra investigación cuyos resultados aún no se conocen. 